\title{
A comparison of North American and European railway systems
}

\author{
Why Europe needs particular optimization models for railway freight traffic
}

\author{
Uwe Clausen · Robert Voll
}

Received: 4 April 2012 / Accepted: 16 January 2013 / Published online: 14 February 2013

(C) The Author(s) 2013. This article is published with open access at SpringerLink.com

\begin{abstract}
Purpose In comparison to North America, railway companies in Europe are confronted with strong economic issues in running their wagonload traffic. The purpose of this paper is an analysis how infrastructural and institutional differences affect planning issues and economic efficiency. Method A particular decision problem from railway freight traffic, the Railroad Blocking Problem (RBP), is considered. It is a typical consolidation problem from wagonload traffic, where transport and reclassification costs have to be balanced. A short survey on corresponding optimization models is given. An analysis of the cost structures shows that the share of fix costs in the total transport costs is much higher in Europe than in North America. The objective functions of the models take this into account. They effect that North American models mainly focus on finding short ways for each wagon, while European ones focus on consolidation and high train utilization. The possibility to transfer North American planning concepts to Europe is discussed. Results Due to institutional and infrastructural reasons, train capacities and cost structures in North American and European railway freight traffic differ from each other. This results in very centralized railway traffic in Europe. According to the different circumstances, the planning issues differ
\end{abstract}

\footnotetext{
U. Clausen

Fraunhofer Institute for Material Flow and Logistics, Dortmund, Germany

e-mail: uwe.clausen@iml.fraunhofer.de

U. Clausen $\cdot$ R. Voll $(\bowtie)$

Institute of Transport Logistics, TU Dortmund University, Dortmund, Germany

e-mail: voll@itl.tu-dortmund.de
}

from each other, too. A direct transfer of decision concepts is not possible.

Conclusion Although the planning issues strongly differ from each other, Europe can learn a lot from North American railway planning models. The potentials of decentralized traffic in European railway freight traffic should be investigated.

Keywords Railway freight traffic · Consolidation · Mathematical optimization

\section{Introduction}

Railway is one of the most important modes for freight transport nearly all over the world. More than nine trillion of ton kilometers were transported by railway worldwide in 2010 [8]. The relevance of railway freight traffic is still growing due to economic and ecological reasons. North American railway companies can profit from this development and run their freight business very successfully. In contrast, European railroad traffic is confronted with strong economic issues. Especially, the pressure on wagonload traffic has been increasing in the last years, so that some European countries have already begun to abolish wagonload traffic.

In this paper we will analyze the impact of systemic differences in railway freight traffic between North America and Europe. We will focus on tactical planning processes and formulate thesises concerning decision support systems. We want to figure out how economic circumstances influence the decision process. A survey on scientific literature about certain tactical planning aspects will point out which methods from North American railway systems can be transferred to Europe. 
Section 2 provides information about planning processes in wagonload traffic in general, followed by a survey with annotations in Section 3. Section 4 deals with infrastructural and conceptional differences between North American and European Railroad traffic. At last, we formulate our conclusions about European railroad models, which are the main contribution of this paper.

\section{Railroad planning problems}

We focus on planning problems arising from wagonload traffic, which functions as follows: A customer wants to transport a small group of wagons from A to B by train. The number of wagons is too small to justify direct transport. Therefore, it is necessary to bundle them with wagons from other origin-destination-pairs (relations) for certain parts of their routes. Trains can be separated and sorted to new trains in classification and marshalling yards which are distributed all over the railway network. The sorting process (called reclassification) is very expensive and time-consuming. Hence, it is necessary to balance reclassifications and transport distance. Transport costs per kilometer depend on several factors, e.g., personnel, energy and infrastructural costs.

Several aspects of wagonload traffic have to be managed by railway operators. According to Assad [2], they are usually categorized into three time horizons: strategic, tactical and operational decisions. The strategic decisions are mainly infrastructural decisions like yard allocation or building new tracks. The tactical horizon deals with the composition of wagons to trains, routing of aggregated wagon flows and mid-term personnel planning. Timetabling, track and locomotive scheduling, empty car distribution and yard control belong to the operational decisions in railroad freight traffic. The planning steps are often arranged hierarchically. Nevertheless, there are examples for integrated planning approaches, e.g. by Zhu et al. in [15].

We will focus on a certain tactical planning problem in this paper, which can be characterized as follows: A railroad network with capacities, a list of origin-destination-requests and a cost function for the system-wide costs are given. The question is, how wagon flows shall be routed through the network minimizing the total costs. The problem is often referred to as the Blocking Problem.

\section{Survey on railway models}

This section will summarize scientific literature about the Blocking Problem, which was defined above. Our survey differs from former surveys about this field of research, like e.g., by Toth and Vigo [7], because it stresses certain aspects that will be necessary for our comparison of North American and European planning problems in railway freight traffic.

Railroad networks can be modelled as directed graphs. The network nodes mark stations or yards in the physical network, while arcs represent the railway connections between them. This modelling approach is the base of all models presented in this section.

We listed typical constraints of the considered problem in Table 1. The objective functions of the models are discussed below. The property 'split table' is marked if the model allows to split the wagonflow of particular relations and send its wagons along more than one path to its destination. The so called consolidation effect, which was already described by Assad [2], Fuegenschuh [9] and Voll [14] is denoted in the second row. It will turn out to be a key aspect in our comparison of North American and European models. 'Time limit' means a constraint restricting the maximal travel time for each wagon. 'Maximal block lengths' and 'maximal block weights' are self-explaining. The 'arc capacity' is a restriction either on the number of wagons or the number of trains on an arc. The last constraint type mentioned is 'pure strategy'. This is a special condition which is used, e.g., in German railroad traffic. It forces wagons with the same destination which meet each other in a node to use a common route for the rest of their journey. It is equivalent to the condition that there is exactly one path from each node to a particular sink node.

Moreover, all models contain constraints concerning classification limits for each node. They are measured in the number of cars than can be handled or the number of outgoing blocks which can be set up per time unit, respectively. Flow conservation laws are included in each model. They are necessary to fulfill all requests.

The lower part of Table 1 summarizes the cost terms incorporated in the objective function. Mostly, the models consider either car costs or train costs. This structural detail is important for our later argumentation. The appearance of train cost terms in the objective function strongly correlates with the consolidation property of the model. Furthermore, there are some other cost terms used in some of the models. All objective functions contain reclassification costs. Moreover, Bodin [4] and Keaton [10] model delay costs by non-linear terms. They assume that reclassification time and costs must take into account congestion effects inside the yards, i.e., handling-times per unit increase with the number of wagons in the yard. This makes the model more realistic, but results in a much higher computational complexity. Large instances become hardly treatable due to non-linearity. All other objective functions are linear. 
Table 1 Constraints included in models

\begin{tabular}{|c|c|c|c|c|c|c|c|}
\hline & Bodin [4] & Assad [2] & Keaton [10] & Newton ** [11] & Ahuja [1] & Fuegenschuh [9] & Voll [14] \\
\hline Splittable & $\mathrm{x}$ & $\mathrm{x}$ & & $\mathrm{x}$ & & & \\
\hline Consolidation & & $\mathrm{x}$ & $\mathrm{x}$ & & & $\mathrm{x}$ & $\mathrm{x}$ \\
\hline Time limit & $*$ & $*$ & $\mathrm{x}$ & & & $\mathrm{x}$ & \\
\hline Max. block length & $\mathrm{x}$ & & $\mathrm{x}$ & & & $\mathrm{x}$ & $\mathrm{x}$ \\
\hline Max. block weight & & & & & & $\mathrm{x}$ & $\mathrm{x}$ \\
\hline Arc capacity & & $\mathrm{x}$ & $\mathrm{x}$ & $\mathrm{x}$ & $\mathrm{x}$ & & \\
\hline Pure strategy & $\mathrm{x}$ & & $\mathrm{x}$ & & & $\mathrm{x}$ & \\
\hline Train costs & & $\mathrm{x}$ & $\mathrm{x}$ & & & $\mathrm{x}$ & $\mathrm{x}$ \\
\hline Car costs & $\mathrm{x}$ & & $\mathrm{x}$ & $\mathrm{x}$ & $\mathrm{x}$ & $\mathrm{x}$ & \\
\hline Reclassification costs & $\mathrm{x}$ & $\mathrm{x}$ & $\mathrm{x}$ & $\mathrm{x}$ & $\mathrm{x}$ & $\mathrm{x}$ & $\mathrm{x}$ \\
\hline
\end{tabular}

*penalized in objective function

**Barnhart et al. use the same model in [3]

\section{Comparison of European and North American railways}

We will list infrastructural and organizational differences between European and North American railway systems in this section. We will focus on differences which tackle tactical planning processes. A more general overview is given by Posner [12].

Nearly all European railway networks are former or current property of the national states. In spite of further developing liberalization in Europe, railway infrastructure is still held by public institutions in most European countries. The liberalization enforced fair access to infrastructure for all companies in the market. This resulted in a growing number of actors in the market and a higher internationalization of the railway freight sector. In contrast, North American railway networks always belonged to the rail freight operators, which are private organisations as well. Regularization mainly took place in terms of rules for freight rates and prohibition of customer discrimination in the USA. The abolishment of this regularization resulted-in contrast to Europe-in a strongly decreasing number of railroad companies. Further information about liberalization, especially in Europe, is given by Eisenkopf et al. [5].

As a result of the ownership structure concerning infrastructure, North America has separate rail networks for freight traffic. In Europe, freight and passenger traffic share the same networks. Moreover, passenger traffic is almost always prioritized to freight traffic in Europe. Hence, freight trains have only two possibilities. They can either be moved at night, when passenger traffic is strongly reduced or they have to draw aside onto bypass tracks when faster passenger trains are going to overtake them. Since it is impossible to execute the whole freight traffic at night, the lengths of the bypass tracks automatically restrict train lengths (e.g., to $630 \mathrm{~m}$ in Denmark and $700 \mathrm{~m}$ in Germany). The impact of this policy is dramatic to freight traffic. While North American trains do not have a certain length restriction, European railroad companies suffer from low train capacities and cannot benefit from economies of scale so much. Moreover, European railway infrastructure usually does not permit the application of doubledeck-trains. Hence, train capacities are much lower in Europe. This affects the price structure for rail transport. Average costs per ton kilometer are ten times higher in Europe than in North America [13]. Accordingly, European cost structures significantly differ from North American ones. Due to higher prices per ton kilometer, reclassifications have a relatively weaker impact on total costs in Europe. The balance between transportation and reclassification costs is influenced by infrastructural and institutional circumstances. The resulting impacts on planning processes will be analyzed in the next section.

\section{Conclusions for planning processes}

North American railroad companies are able to move wagons through their networks much cheaper than European ones can. We will analyze consequences for planning problems on the two continents in this section.

As already mentioned in the previous section, movement costs have a lower share in the total costs in North America. Accordingly, planning models created for American railroad traffic in the last decade by Ahuja [1], Newton [11] and also Bodin [4] neglect train costs and calculate costs individually for each car. The result of this decision is that car routes are computed as a parallel constrained shortest paths for all cars. If there were no restrictions on the yard and arc capacities, all wagons would take their shortest path through 
the network. This aspect strictly correlates with the absence of the bundling effect described by Assad [2] and Voll [14]. Due to the cost structure in European railroad traffic, solutions without bundling would cause enormous costs. Since railways do not belong to the operator, they must be rented for each usage. This results in large fix costs, which have a share of up to $50 \%$ in costs for running a train. Thus, costs per trainkilometer do not depend significantly on the degree of capacity utilization. Hence, models in which costs are dominated by car costs do not reflect reality sufficiently in Europe.

Nevertheless, European railroad deciders can learn a lot from North America. Due to the comparatively high prices per trainkilometer, European railroad companies see themselves confronted with enormous competition from road transport. Distances between sender and receiver in Europe are on average much shorter than in larger countries like the USA, which cover more than twice the area of the whole European Union. Shorter distances reduce the advantages of railway compared to road transport unless special measures are applied, as e.g., described by Clausen and Kochsiek [6]. Consequently, European railroad companies suffer from low margins from freight business. Especially wagonload traffic with its low volumes is often not competitive. Railway freight traffic and especially wagonload traffic must be managed more efficiently in order to keep up its importance in freight business.

The abolition of the aforementioned pure strategy included in Bodin [4], Keaton [10] and Fuegenschuh [9] might be a key to make European railroad systems more flexible and more efficient. Pure strategy is often used because of historical reasons. Work in the shunting yards used to be easier to coordinate when wagon routes could be derived from their destinations. This was an advantage in times when decisions were made by hand. But nowadays more and more work inside the yards is coordinated by software support systems. Thus, reduction of human mistakes by an easier planning system, i.e. pure strategy, is an outdated strategy. According to the last arguments, we advance the thesis that the pure strategy, which enforces a unique successor node for relations with common destinations, should be abolished in European railway planning processes. European railway operators should learn from North American production systems and customize existing ideas to their own needs. New concepts adapting ideas and knowledge from North American railroads are needed to prepare the European railroad systems for the future.

\section{Summary}

In contrast to North America, European freight trains have to share the railway tracks with passenger trains, which are almost always preferred. This affects the price structure for rail transports in Europe. We analyzed a selection of optimization models for wagon flows. We derived two thesises about the portability of North American planning approaches. Firstly, European models must provide a more balanced trade-off between transportation and classification costs. Consideration of train costs is essential. Otherwise, solutions found will not be advantageous in reality. Secondly, it might be time to abolish the old-fashioned pure strategy to make the planning process more flexible. Due to further increasing demands in the transport sector, railway must stay competitive to other transport modes. There is a strong need for further research in railway planning mechanisms which are specialized for European requirements. Scientific developments and new technologies must be applied consequently to ensure future success and competitiveness of railroad freight traffic.

Acknowledgments The presented ideas mostly arised from the project 'Guided Planning-Tool For Car Grouping in Railroad Freight Traffic" within the "Effiency Cluster Logistics Ruhr" (01IC10L26A) funded by the German Federal Ministry of Education and Research (BMBF) in cooperation with the DB Mobility Logistics AG.

Open Access This article is distributed under the terms of the Creative Commons Attribution License which permits any use, distribution and reproduction in any medium, provided the original author(s) and source are credited.

\section{References}

1. Ahuja RK, Jha KC, Liu J (2007) Solving real-life railroad blocking problems. Interfaces 37(5):404-419. doi:10.1287/inte.1070.0295

2. Assad A (1980) Modelling of rail networks: toward a routing/makeup model. Transp Res Part B: Methodol 14(12):101114

3. Barnhart C, Jin H, Vance P (2000) Railroad blocking: a network design application. Oper Res 48(4):603-614

4. Bodin L, Golden B, Schuster AD, Romig W (1980) A model for the blocking of trains. Transp Res Part B: Methodol 14(12):115120

5. Eisenkopf A, Kircher C, Jarzembowski G, Ludewig J, Rothengatter W, McCullough G (2006) The liberalisation of rail transport in the EU. Intereconomics 41(6):292-313

6. Clausen U, Kochsiek J (2008) Einbindung des Verkehrsträgers Schiene in die Logistikketten. Der Eisenbahningenieur 59(6):4851

7. Cordeau JF, Toth P, Vigo D (1998) A survey of optimization models for train routing and scheduling. Transp Sci 32(4):380-404

8. de Jong L, Markovic-Chenais S (2011) Press Release No. 18/2011. UIC International Union of Railways, Paris

9. Fügenschuh A, Homfeld H, Schülldorf H (2009) Single car routing in rail freight transport. Dagstuhl Seminar Proceedings 09261, Schloss Dagstuhl-Leibniz-Zentrum für Informatik, Deutschland 
10. Keaton MH (1989) Designing optimal railroad operating plans: lagrangian relaxation and heuristic approaches. Transp Res Part B: Methodol 23(6):415-431

11. Newton HN (1996) Network design under budget constraints with application to the railroad blocking problem. Dissertation. Auburn University, Auburn

12. Posner III H (2008) Rail freight in the USA: lessons for continental Europe. CER Essay Series

13. Schade W, Doll C, Maibach M, Peter M, Crespo F, Carvalho D, Caiado G, Conti M, Lilico A, Afraz N (2006) Analysis of the con- tribution of transport policies to the competitiveness of the EU economy and comparison with the United States: COMPETE final report. Fraunhofer ISI, Karlsruhe

14. Voll R, Clausen U (2011) A blocking model with bundling effects respecting multiple od-matrices. Proceedings of the 4th International Conference on Experiemnts/Process/System Modeling/imulation/Optimization, Athens

15. Zhu E, Crainic T, Gendreau M (2011) Scheduled service network design for freight rail transportation. CIRRELT publications, Montreal 